\title{
Prácticas comerciales desleales, acciones individuales y armonización plena
}

\author{
Unfair Commercial Practices, Private Enforcement \\ and Full Harmonisation \\ Donato Maria Matera \\ Teaching Assistant in Private Law \\ at the University LUM «Jean Monnet» of Bari-Casamassima
}

Sumario: I. Introducción. El problema.-II. La Directiva sobre «prácticas comerciales abusivas» y el principio de full harmonisation. 1. Full harmonisation y acciones individuales. 1.1. Estados Miembros que no han adoptado acciones individuales. El caso italiano. 1.2. Estados Miembros que adoptaron acciones individuales para los consumidores.III. Efectividad de la tutela y necesidad de full harmonisation en las acciones civiles contra las prácticas desleales: el recurso al sistema del derecho contractual europeo.-IV. Directivas europeas en tema de consumidores e interacción con la disciplina de prácticas desleales. 1. La Directiva 93/13/EC sobre cláusulas abusivas e invalidez de las cláusulas. 2. La Directiva 1999/44/CE y la falta de conformidad de los bienes de consumo. 3. La Directiva 2011/83/EU y el doble sistema de tutela.-V. Prácticas comerciales desleales y el deber de buena fe.-VI. Conclusiones.

Resumen: El sistema de las acciones individuales de derecho privado a disposición de los consumidores que hayan estipulado un contrato bajo la influencia de una práctica comercial desleal no queda disciplinado por la Directiva 2005/29/ CE y parece hoy fragmentado y, a menudo, inadecuado. Sin embargo, con un análisis más minucioso del ordenamiento europeo, se puede observar cómo, aunque de manera indirecta, muchas de las Directivas relativas al derecho de consumidores facilitan instrumentos eficaces a disposición de los mismos consumidores. En los casos en los que no haya esta interacción, de todos modos, es posible garantizar tutela recurriendo al principio general de buena fe.

Palabras clave: Prácticas comerciales desleales, acciones individuales, armonización plena, buena fe.

Abstract: The system of individual remedies available to consumers who have stipulated a contract under the influence of an unfair commercial practice is not disciplined by Directive 2005/29/EC. As a result, it seems today fragmented 
and often inadequate. However, to a more detailed analysis of the European legal system, it becomes clear that many of the directives about consumer protection, even if indirectly, provide these consumers with efficient tools; as a result, consumers have efficient remedies to react to the contract undermined from an unfair commercial practice. In cases where there is not such interaction, it is possible to guarantee protection by recourse to the general principle of good faith.

Keywords: Unfair commercial practices, individual remedies, full harmonisation, good faith.

\section{Introducción. El problema}

Como es sabido, la Directiva 2005/29/CE introdujo la prohibición para los comerciantes de adoptar prácticas comerciales desleales en sus relaciones con los consumidores.

Si bien este acto normativo, utilizando la técnica de la llamada armonización plena, ha introducido una noción amplia y eficaz de «práctica desleal» $\mathrm{y}$ ha incluido acciones para el public enforcement, no ha establecido acciones individuales para los consumidores que hayan concluido un contrato al amparo de una práctica abusiva; de un modo distinto, se ha dejado a los Estados Miembros la elección sobre la posibilidad de introducir una acción ad hoc, con el fin de respetar las diferencias entre los Derechos privados nacionales.

Como se pone de manifiesto en este trabajo, en una primera observación del escenario jurídico europeo, la consecuencia de la falta de full harmonisation en las acciones individuales privadas parece que ha sido la de un sistema altamente fragmentario en este ámbito; a Estados que no han adoptado acciones individuales específicas para la violación de la prohibición establecida por la Directiva se contraponen Estados que sí lo han hecho, recurriendo a instrumentos que ya existían o creando otros nuevos. Esta fragmentación, sin embargo, corre el riesgo de comprometer la efectividad de la protección de los consumidores y de no promover el desarrollo del mercado único, que es una finalidad expresamente mencionada por la Directiva.

Parece oportuno plantearse - como se intenta hacer en este trabajosi, en una observación más específica del ordenamiento jurídico europeo, ya no existen acciones que los consumidores puedan utilizar para alcanzar una plena y efectiva protección contra las prácticas abusivas. Dicho estudio tendrá necesariamente en cuenta el acquis communautaire ya existente en tema de consumidores y los principios que constituyen su base. 
A pesar de la amplitud del concepto de «práctica comercial desleal», las prácticas a las que se hará referencia en el presente trabajo son las ocurridas en la fase precontractual y que tienen como consecuencia directa la estipulación de un contrato que, de otra manera, el consumidor no hubiera estipulado o que hubiera estipulado en condiciones distintas.

\section{La Directiva sobre «prácticas comerciales abusivas» y el principio de full harmonisation}

La Directiva 2005/29/CE ${ }^{1}$ ha consagrado en el Derecho europeo la prohibición para los empresarios de recurrir a «prácticas comerciales desleales» que afectan a los intereses económicos de los consumidores.

Calificada con elocuencia como el instrumento más completo y potente adoptado por la Unión Europea en el ámbito del Derecho de los consumidores ${ }^{2}$, en efecto se trata de un acto comunitario de especial relevancia, porque ha sido el primero en prever una noción tan amplia y general como la de «práctica desleal» ${ }^{3}$ y en introducir una obligación - aunque debatida y discutida ya sea a la hora de aprobar el texto normativo ya sea por la doctrina ${ }^{4}$ - de alcance tan amplio para el comerciante como la de actuar conforme a la buena fe en las relaciones con los consumidores y en todas las fases de la relación con estos ${ }^{5}$.

${ }^{1}$ Directiva 2005/29/CE del Parlamento Europeo y del Consejo, del 11 mayo de 2015.

2 Mateja Durovic, «The Subtle Europeanization of Contract Law: The Case of Directive 2005/29/EC on Unfair Commercial Practices», European Review of Private Law, n. ${ }^{\circ} 5$ (2015): 715-16.

${ }^{3}$ Que, como es sabido, se define en la propia Directiva como todos aquellos comportamientos (actos, omisiones, conductas o manifestaciones, o comunicaciones comerciales, incluidas la publicidad y la comercialización) de un comerciante que sean contrarios a los requisitos de la diligencia profesional y que distoriona o puede distorsionar de manera sustancial el comportamiento económico de los consumidores en el mercado (cfr. arts. 2 , let. d) y 5(2) de la Directiva 2005/29/CE).

${ }^{4}$ Hugh Collins, «Harmonization by Example: European Laws against Unfair Commercial Practices», The Modern Law Review 73, n. ${ }^{\circ} 1$ (2010): 93; unos Estados Miembros, como el Reino Unido, de hecho, albergaron dudas, que llevaron a un debate sobre el tema, sobre la nocividad de una cláusula general tan amplia y por esto de sentido tan vago.

${ }^{5}$ De hecho, es sabido que las disposiciones de la Directiva se aplican solo a los llamados contratos B2C. La prohibición general de prácticas desleales no se aplica en cambio - en la intención del legislador europeo - a los contratos B2B (si bien Alemania y Austria hubieran manifestado serias dudas justo sobre este punto; v. Hans-W. Micklitz, «Unfair Commercial Practices and Misleading Advertising», en European Consumer Law, ed. por Norbert Reich, Hans-W. Micklitz, Peter Rott y Klaus Tonner (Cambridge: Intersentia, 2014), 79). No obstante, hay Estados Miembros que han extendido esta disciplina también a los contratos $\mathrm{B} 2 \mathrm{~b}$, es decir a los contratos entre profesionales en los que uno de los dos se encuentra en posición de ventaja, porque económicamente y estructuralmente más fuerte (en este sentido, v. art. 19, comma 1 del Codice del Consumo italiano, d.lgs. 6 septiembre de 2005, n. 206). 
Como es sabido, la legislación introduce un sistema de control «piramidal», por el cual una conducta del comerciante - antes, durante o después de la estipulación de un contrato- para poder considerarse leal y, por lo tanto, lícita, se someterá a un triple control. En primer lugar, se confrontará con las treinta y una prácticas comerciales que se consideran desleales en cualquier circunstancia, contempladas en la Black list del Anexo I de la Directiva. En segundo lugar, si no encaja con éstas, se comparará con las disposiciones sobre las dos principales prácticas desleales (prácticas engañosas y prácticas agresivas). Finalmente, si aún este segundo control diera éxito negativo, se examinaría sobre la base de la cláusula general de deslealtad del artículo 5.

Esta Directiva ha sido adoptada con una doble finalidad, expresamente especificada en el art. 1 de la misma: contribuir al buen funcionamiento del mercado interior y alcanzar un nivel elevado de protección de los consumidores. La regulación de las prácticas comerciales desleales, antes de la introducción de esta normativa, quedaba muy fragmentada bajo un análisis comparado con los Derechos nacionales y esto contribuía, por una parte, a disminuir la confianza de los consumidores en las operaciones económicas, especialmente con carácter transnacional; y, por otra, a incrementar las costas para las empresas que hubieran querido operar en este ámbito, dada la incertidumbre sobre las disposiciones nacionales que se podían aplicar a sus políticas económicas ${ }^{6}$. En definitiva, el acto en cuestión tiene como finalidad la adecuada protección de los consumidores, que puede suscitar en ellos más confianza en el mercado europeo y simplificar la actividad de las empresas, reduciendo la incertidumbre normativa en la que quedaban obligadas a actuar. Se quería favorecer, de esta manera, el desarrollo del mercado único y el incremento de las operaciones comerciales en su interior ${ }^{7}$.

El instrumento que ha sido elegido por el legislador comunitario para alcanzar este objetivo ha sido la llamada armonización plena (full harmonisation) de las leyes nacionales sobre prácticas desleales, es decir, los Estados Miembros deben respetar el estándar de tutela indicado por la Directiva, ya que no pueden adoptar regulaciones que aporten a los consumidores un nivel de protección mayor - o menor - de lo establecido y tienen que eliminar las regulaciones preexistentes que contrasten con este ${ }^{8}$.

${ }^{6}$ Cfr. Considerando (2), (3), (4), (5) de la Directiva.

${ }^{7}$ Micklitz, «Unfair Commercial Practices and Misleading Advertising», 77.

8 Esta suposición fue confirmada da la misma jurisprudencia de la CJE. V., especialmente, Corte just., asuntos acumulados C-261/07, TB-NAB NV contra Total Belgium y C-299/07, Galatea BVBA contra SonomaMagazines BelgiumNV, de 23 abril de 2009, accesibles online en www.curia.eu. 
Sin profundizar en el tema, nos limitaremos a observar cómo al principio el recurso de full harmonisation en esta normativa fue un punto tan debatido como innovador ${ }^{9}$ en el acquis comunitario sobre Derecho de consumidores y marcó una nueva tendencia en la legislación europea, auspiciada y perseguida por la misma Comisión ${ }^{10}$.

\section{Full harmonisation y acciones individuales}

El principio de armonización plena de la disciplina de prácticas desleales, sin embargo, incluye excepciones. En primer lugar, los Estados Miembros pueden imponer requisitos más exigentes o más restrictivos que los previstos en la Directiva por lo que respecta a los servicios financieros y a los bienes inmuebles ${ }^{11}$.

Igualmente, no queda armonizado en manera plena el llamado private enforcement, esto es el Derecho privado de los Estados Miembros relacionado con las acciones individuales aseguradas a los consumidores que hayan sido víctimas de prácticas comerciales desleales y que, bajo el amparo de estas prácticas, hayan concluido una operación comercial. De hecho, en este sentido la legislación europea guarda silencio. El artículo 3(2) de la Directiva se limita a establecer cómo ésta se entiende «sin perjuicio del Derecho contractual, y en particular de las normas relativas a la validez, la formación o el efecto de los contratos».

Según lo previsto en esta norma, no hay obligación para los Estados Miembros - a la hora de trasponer la Directiva - de proporcionar a los consumidores víctimas de prácticas abusivas acciones privatistas, en particular con la finalidad de invalidar el contrato resultante; y tampoco las normas europeas sobre prácticas desleales deberían tener, en la intención del legislador europeo, repercusiones directas sobre el Derecho privado nacional ${ }^{12}$.

9 Thomas Wilhelmsson, «Harmonizing Unfair Commercial Practices Law: The Cultural And Social Dimensions», Osgoode Hall Law Journal 44, n. ${ }^{\circ} 3$ (2006): 477.

10 Wilhelmsson, «Harmonizing Unfair Commercial Practices Law: The Cultural And Social Dimensions», 477.

11 V. art. 3(9) Directiva 2005/29/CE.

12 Cfr. sobre el tema Marios Koutsias y Chris Willet, «Uk implementation of the Unfair Commercial Practices Directive», en The European Unfair Commercial Practices Directive. Impact, Enforcement Strategies and National Lecal Systems, ed. por Willem van Boom, Amandine Garde y Orkun Akseli (Surrey: Ashgate, 2014): 30; Marios Koutsias y Chris Willet, «The Unfair Commercial Practices Directive in the UK», Erasmus Law Review, n. ${ }^{\circ} 5$, (2012): 244; v. también Nadia Zorzi Galgano, «Sulla invalidità del contratto a valle di una pratica commerciale scorretta», Contratto e Impresa, n. ${ }^{\circ}$ 4-5 (2011): 922. 
El estudio realizado permite deducir que se quiso realizar una estricta separación entre la disciplina de las prácticas desleales y el Derecho privado de los Estados Miembros ${ }^{13}$, todo esto con la finalidad de respetar las distinciones existentes en el ámbito del Derecho nacional de los distintos Estados $^{14}$.

Al mismo tiempo, sin embargo, esta disposición ha dado lugar a incertitumbre sobre el impacto de la nueva disciplina de las prácticas desleales en el Derecho privado - y en particular en el Derecho contractual- de los Estados Miembros, lo que llevó a la doctrina a definirla como el verdadero «talón de Aquiles» del proyecto de armonización del Derecho europeo sobre unfair marketing practices ${ }^{15}$.

Aunque con las debidas diferencias, que aquí no se quieren negar y que por la misma naturaleza de la Unión Europea no pueden desaparecer ${ }^{16}$ (también como resultado de las distintas formas con las que los Estados han traspuesto la Directiva en los ordenamientos nacionales ${ }^{17}$ ), tanto la disciplina general de las prácticas abusivas como las acciones del llamado public enforcement quedan bastante armonizadas. Como cabía esperar, la disciplina de las acciones civiles para los contratos viciados por prácticas desleales queda, en cambio, profundamente fragmentada. A Estados que no han introducido acciones específicas de carácter individual para la violación de esta normativa $-\mathrm{y}$ que así han dejado la cuestión a la regulación de las normas generales de contratos o de las leyes nacionales de consumidores - se contraponen Estados que sí lo han hecho. Sin embargo, también entre estos últimos, como se verá a continuación, se pueden notar diferencias muy grandes a la hora de elegir la acción adoptada para garantizar protección a los consumidores.

Un análisis rápido de estas normativas facilitará al lector obtener un marco claro del fenómeno.

13 Durovic, «The Subtle Europeanization of Contract Law: The Case of Directive 2005/29/EC on Unfair Commercial Practices», 716.

14 Stephen Weatherill, EU Consumer Law and Policy (Cheltenham: Edward Elgar Publishing, 2013), 246.

15 Collins, «Harmonization by Example: European Laws against Unfair Commercial Practices», 93.

16 Sobre las necesarias diferencias en el ámbito de derecho europeo, debido a las diferencias culturales y de los tejidos sociales, v. el ya citado Wilhelmsson, «Harmonizing Unfair Commercial Practices Law: The Cultural And Social Dimensions», 461-500

17 Cfr. a este respecto: Civic Consulting, Study on the application of Directive 2005/29/ EC on Unfair Commercial Practices in the EU, Part 2 - Country Reports, Synthesis report to the European Commission, Final Report, 22 diciembre de 2011, http://www.civic-consulting. de/reports/ucpd_study_country_reports.pdf. 


\subsection{Estados Miembros que no han adoptado acciones individuales. El caso italiano}

A pesar de las diferencias, que ya se han mencionado, la mayoría de los Estados Miembros no ha introducido acciones individuales a disposición de los consumidores víctimas de prácticas desleales ${ }^{18}$. En estos Estados no se introdujo legislativamente una nueva acción, ni se eximieron acciones ya existentes que tuvieran el alcance de invalidar total o parcialmente el contrato «viciado» por una práctica desleal o que proporcionaran al consumidor víctima de esta práctica la indemnización por los daños consecuentes.

Por lo tanto, no se quiso crear una yuxtaposición entre la disciplina de las prácticas desleales y el derecho privado nacional, dado que el comportamiento desleal del empresario no tiene en sí mismo efectos directos sobre la validez o eficacia del contrato ${ }^{19}$.

Sin embargo, ya de los primeros comentarios a la Directiva 2005/29/CE emergía la asonancia en el ámbito contractual entre los nuevos conceptos introducidos por la legislación europea y los de tradición codificadora sobre los vicios del consentimiento ${ }^{20}$. En estos ordenamientos, no se le habría dejado sin tutela al consumidor, sino que una práctica desleal hubiera viciado la elección del consumidor, de tal modo que, cumplidos los requisitos, habría podido actuar para obtener la invalidez del acto negocial.

Quedaba al mismo tiempo claro que no siempre la disciplina de vicios del consentimiento habría podido ser de fácil acceso para el consumidor ${ }^{21}$, porque el Derecho comunitario y el Derecho codificado - en el que, como

18 V. otra vez Civic Consulting, Study on the application of Directive 2005/29/EC on Unfair Commercial Practices in the EU.

19 V. Simon Whittaker, «The Relationship of the Unfair Commercial Practices Directive to European and National Contract Laws», en The Regulation of Unfair Commercial Practices under EC Directive 2005/29. New Rules and New Techniques, ed. por Stephen Weatherill y Ulf Bernitz (Oxford: Hart Publishing, 2007), 151-154.

${ }^{20}$ V., sobre todos, Collins, «The Unfair Commercial Practices Directive», 425-427.

${ }^{21}$ Como se observará en la continuación del trabajo, esta dificultad de interacción entre disciplinas ha sido particularmente observada en el ordenamiento anglosajón, debido a la considerable dificultad para los consumidores a la hora de recurrir a los conceptos tradicionales de «misrepresentation», «duress» e «undue influence». Todo esto llevó al legislador inglés, en 2014, a modificar el acto de transposición de la Directiva, introduciendo una nueva acción individual a disposición del consumidor victima de prácticas abusivas. Sobre este tema, antes de la introducción de la acción individual, v. Koutsias y Willet, «Uk implementation of the Unfair Commercial Practices Directive», 21-22 y en particular 3239; Geraint Howells, «Unfair Commercial Pratices - Future Directions», en European Private Law, ed. por Renier Schulze y Hans Schulte-Nölke (Munich: Sellier 2011), 137; Bert Keirsbilck, The New European Law of Unfair Commercial Practices and Competition Law (Oxford-Portland: Hart Publishing 2011): 468-469; Collins, «Harmonization by Example: European Laws against Unfair Commercial Practices», 113-117. 
es sabido, se encuentra el tema de los vicios del consentimiento- tienen matices muy diferentes ${ }^{22}$; de hecho, estos últimos toman en consideración una relación contractual en la que las partes se encuentran en una situación de paridad substancial, lo que en los llamados contratos B2C no existe.

La doctrina europea, tras constatar la insuficiencia de los conceptos tradicionales de «vicios de consentimiento» ya existentes en los ordenamientos nacionales, planteó entonces la posibilidad - por los tribunales - de desarrollar estos conceptos, es decir, su extensión más allá de su alcance clásico, lo que habría asegurado una tutela más efectiva para el consumidor ${ }^{23}$.

A este propósito nos parece especialmente ilustrativo el caso italiano. Conforme a lo expuesto, también en Italia, con ocasión de los primeros comentarios de la Directiva 2005/29/CE, se observó la asonancia entre la disciplina de las prácticas comerciales abusivas y la de los «vizi del consenso», y de manera particular con el «dolo» y la «violenza» ${ }^{24}$. Quedaba pues en evidencia que estas disciplinas habrían sido destinadas a interactuar entre ellas o que, de cualquier modo, la nueva normativa introducida por la Directiva habría llevado, de todos modos, a una invalidez o ineficacia del contrato como resultado de una voluntad no totalmente libre y/o informada del consumidor ${ }^{25}$.

Después de la transposición en el ordenamiento jurídico italiano de la Directiva 2005/29/CE, en el Codice del Consumo (Cod. Cons.) no quedaba previsto ninguna acción individual privatista para los consumidores víctimas de prácticas comerciales desleales ${ }^{26}$. De hecho, el legislador italiano se

22 A este respecto, cfr. Aurelio Gentili, «Pratiche sleali e tutele legali: dal modello economico alla disciplina giuridica», Rivista di diritto privato, n. ${ }^{\circ} 3$ (2010): 45-48.

23 En ámbito internacional v. aún, Collins, «The Unfair Commercial Practices Directive», 424; para una perspectiva del derecho contractual europeo, con particular enfoque en derecho frances, v. Simon Whittaker, «The Relationship of the Unfair Commercial Practices Directive to European and National Contract Laws», 139; para la perspectiva de common law v. Collins, «Harmonization by Example: European Laws against Unfair Commercial Practices», 114;

${ }^{24}$ En este sentido v. Mario Nuzzo, «Pratiche commerciali sleali ed effetti sul contratto: nullità di protezione o annullabilità per vizi del consenso?», en Le pratiche commerciali sleali, Direttiva comunitaria ed ordinamento italiano, ed. por Ernico Minervini y Liliana Rossi Carleo (Milano: Giuffrè 2007), 235-243.

${ }^{25}$ Plantea un posible recurso al desistimiento por el legislador italiano, análogamente a los contratos negociados a distancia o fuera de los establecimientos mercantiles, Liliana Rossi Carleo, «Dalla comunicazione commerciale alle pratiche commerciali scorrette», en Le pratiche commerciali sleali, Direttiva comunitaria ed ordinamento italiano, ed. por Ernico Minervini y Liliana Rossi Carleo (Milano: Giuffrè 2007), 1-23, especialmente 23.

En cambio, planteaba una compatibilidad de la nueva disciplina comunitaria con la «nullità di protezione» Aurelio Gentili, «Codice del consumo ed espirit de géométrie», I contratti, (2006): 159-174.

${ }^{26}$ Cfr. art. 19, comma 2, lect. a) Cod. Cons. 
había simplemente limitado - de manera cuestionable - a referirse servilmente al art. 3(2) de la Directiva ${ }^{27}$.

Incluso después de la transposición, se continuó planteando la necesidad de una interacción entre la anulabilidad por vicios del consentimiento y la nueva normativa dictada por los arts. 18 ss. Cod. Cons. Sin embargo, al mismo tiempo se observaba cómo el alcance de las acciones previstas en el Codice Civile no cubría completamente los nuevos casos previstos en la $\mathrm{Di}$ rectiva, ni tampoco respondían a la misma ratio $^{28}$. De esta manera, habría sido posible que en unos casos - tampoco muy raros - la acción de anulabilidad hubiera sido inaccesible para el consumidor que hubiera concluido un contrato al amparo de una práctica desleal, por no cumplirse la plenitud de los requisitos exigidos por la ley italiana para esta acción.

$\mathrm{Si}$, por un lado, en jurisprudencia hay una ausencia casi total de pronunciamientos sobre el tema, por otro la doctrina italiana ${ }^{29}$ ha planteado en di-

${ }^{27}$ La Directiva 2005/29/CE fue transpuesta en el ordenamiento jurídico italiano por el d.lgs. 2 agosto de 2007, n. 146, que, como ya se ha dicho, ha modificado los artículos 18 ss. del Codice dei Consumatori. Sobre la transposición de la Directiva en el ordenamiento italiano, v., entre otros, Giovanni De Cristofaro (ed.), Pratiche commerciali scorrette e codice del consumo (Torino: Giappichelli, 2008).

${ }^{28}$ En particular v. Carlo Granelli, «Le «pratiche commerciali scorrette» tra imprese e consumatori: 1'attuazione della Direttiva 2005/29/CE modifica il codice del consumo», Obbligazioni e contratti, n. ${ }^{\circ} 10$ (2007): 776-784; Gentili, «Pratiche sleali e tutele legali: dal modello economico alla disciplina giuridica», 248.

${ }^{29}$ No es este el lugar para recapitular de manera exhaustiva el debate que tuvo lugar en la doctrina italiana. El principal punto controvertido ha sido la posibilidad de recurrir a acciones contractuales para la estipulación de un contrato al amparo de prácticas desleales, aunque no fueran previstas expresamente por el legislador. La doctrina que se oponía a esta posición, consideraba en cambio solo posible para el consumidor obtener una indemnización para los daños y perjuicios; para una síntesis del debate v. Zorzi Galgano, «Sulla invalidità del contratto a valle di una pratica commerciale scorretta», 926-952. Para bibliografía sobre el tema, en óptica italiana, además de los ya citados, v. entre otros (a parir de los más recientes) Alfredo Belisario, «Pratiche commerciali aggressive», en Diritto privato ed interessi pubblci. Scritti in onore del Prof. L.V. Moscarini, ed. por Nicola Corbo, Mario Nuzzo y Francesco Ricci (Roma: Aracne, 2016), 810-824; Francesco Longobucco, «I rimedi civilistici e le pratiche commerciali scorrette», en Il risarcimento del danno al consumatore, ed. por Paolo Cendon y Cristina Poncibò (Milano: Giuffrè, 2014), 409-424; Alessia Fachechi, Pratiche commerciali scorrette e rimedi negoziali (Napoli: Editoriale Scientifica Italiana, 2012); Carmelita Camadi, «Pratiche commerciali scorrette e invalidità», Obbligazioni e contratti, n. ${ }^{\circ} 6$ (2010): 408-419; Maria Rosaria Maugeri, "Violazione della disciplina sulle pratiche commerciali scorrette e rimedi contrattuali», Nuova giurisprudenza civile commentata, (2008): 1671-1685. Sobre la posibilidad de utilizo de acciones contractuales, como consecuencia de la violación del deber de buena fe, Francesco Ricci, «Buona fede e rimedi», Contratto e impresa/Europa (2013): 632-647; para el caso específico de prácticas desleales, se me permita señalar Donato Maria Matera, «Le pratiche commerciali scorrette e il sistema dei rimedi», en Principi, clausole generali, argomentazione e fonti del diritto, ed. por Francesco Ricci (Milano: Giuffrè Francis Lefebvre, 2018). 
ferentes ocasiones una posible extensión de los conceptos tradicionales relacionados con la anulabilidad del contrato (o en general con la invalidez del mismo), para llegar a facilitar al consumidor y garantizarle una acción individual eficiente contra una elección «irrazionale» causada por el comportamiento desleal del empresario ${ }^{30}$. Si no fuera así, se correría el riesgo de llegar a consecuencias injustas, manteniendo vivo un contrato que el consumidor no quiso - en todo o en parte - y denegándole una tutela adecuada ${ }^{31}$.

El ejemplo italiano puede ser útil para observar cómo, aunque la normativa sobre prácticas abusivas no tenga la finalidad de afectar directamente al Derecho privado de los Estados Miembros, de hecho es inevitable que ésta no tenga repercusiones en la materia. Si bien la mayoría de los Estados europeos no ha introducido acciones individuales específicas para la violación de la prohibición de prácticas desleales, es previsible - si es que este proceso todavía no se ha terminado-que la praxis de los tribunales o los estudios de la doctrina lleven a una extensión o superación de los conceptos tradicionales o, como se explica a continuación, que se introduzcan acciones específicas contra la violación de las normas impuestas por la Directiva.

\subsection{Estados Miembros que adoptaron acciones individuales para los consumidores}

Una minoría de Estados - a los que en 2014 se sumó Inglaterra - en la transposición de la Directiva, en cambio, previeron acciones individuales específicas para el consumidor víctima de prácticas abusivas. Los legisladores nacionales adoptaron soluciones muy distintas entre ellas: en unos casos, de hecho, la consecuencia de una práctica desleal es la invalidez del contrato resultante (o de parte de éste); en otros, su ineficacia ex post.

Luxemburgo, por ejemplo, reconoce al consumidor el derecho de solicitar la nulidad del contrato estipulado bajo el amparo de prácticas desleales - o sólo de las cláusulas resultantes de estas prácticas -, con la particularidad de que dicha nulidad sólo puede invocarse por el propio consumidor ${ }^{32}$.

En Polonia, sin embargo, se contempla la posibilidad de actuar contra el comerciante para solicitar la ineficacia («cancelation») del contrato. Sin

${ }^{30}$ Gentili, «Pratiche sleali e tutele legali: dal modello economico alla disciplina giuridica», 61-63. El mismo Autor precisa que se entiende «scelta irrazionale» aquella elección que no sea libera e informada, v. Aurelio Gentili, Senso e consenso. Storia, teoria e tecnica dell'interpretazione dei contratti, vol. II, (Torino: Giappichelli, 2015), 511.

${ }^{31}$ Se me permita otra referencia a Matera, «Le pratiche commerciali scorrette e il sistema dei rimedi», $\S 2$.

32 Artículo L. 122-8 (2), del Code de la Consommation de Luxemburgo. 
embargo, se ha observado que, especialmente debido a factores económicos y sociales (entre estos, principalmente, la ausencia de conocimiento sobre la existencia de dicha acción, la escasa actitud de los consumidores polacos a recurrir individualmente contra los empresarios y la falta de recursos económicos para ejercitar las acciones), este derecho aún no se ha utilizado ampliamente, sino que sigue siendo una acción prevista en la legislación, sin ninguna efectividad ${ }^{33}$.

También en Francia se ha introducido una acción contractual en las normas de transposición de la Directiva con algunas peculiaridades. En el ordenamiento jurídico francés, se plantea un marco de acciones contractuales individuales a consecuencia de prácticas abusivas con un régimen un tanto particular: si en la estipulación de un contrato con un consumidor el empresario ha utilizado una práctica agresiva, el negocio resultante es nulo ${ }^{34}$. Si, en cambio, la práctica utilizada por el empresario es engañosa o no encaja ni con los casos de prácticas agresivas ni con aquellos de prácticas engañosas, se considera desleal sobre la base del art. 5 de la Directiva 2005/29/CE. En este último caso, si el consumidor quisiera invalidar el contrato o remover sus efectos, dispone de las acciones generales derivadas del contrato (en particular, las relacionadas con el dolo) o de acciones específicas que resulten de disposiciones concretas aplicables al caso.

Suscitan particular atención las soluciones adoptadas por los ordenamientos inglés y belga.

A la hora de transponer la Directiva 2005/29/CE ${ }^{35}$, Inglaterra no había incluido en la normativa ninguna acción individual específica para la violación de la prohibición de prácticas abusivas. En cambio, con la Consumer Protecion (Amendment) Regulation ${ }^{36}$ (CPAR) de 2014, dada la inaccesibilidad de las normas precedentes, prácticamente incomprensibles para los simples consumidores ${ }^{37}$, se atribuyó a estos un triple sistema de acciones. Dicho sistema incluye la posibilidad de rescindir el contrato

${ }^{33}$ Monika Namysłowska, «To B2C or not to B2C. Some Reflections on the Regulation of Unfair Commercial Practices from a Polish Perspective», JCP 36 (2013): 329-342.

34 Artículo 1. 132-10 Code de la Consommation francés. Esta norma prevé que el contrato estipulado bajo el amparo de una práctica comercial agresiva «est nul et de nul effet». De esta manera se extiende el alcance de la acción de nulidad del contrato, pero solo para aquellos contratos viciados por prácticas agresivas.

35 Transpuesta con le Consumer Protection from Unfair Trading Regulations de 2008, 2008/SI/1277.

36 2014/St/870 en http://www.legislation.gov.uk/uksi/2014/870/contents/made.

37 Law Commission and Scottish Law Commission, Consumer Redress for Misleading and Aggressive Practices (Law Com N. . 332, 2012 / Scot Law Com N. ${ }^{\circ} 226,2012$ ), 23 y siguientes; v. Zofia Bednarz, «Acciones individuales a disposición de los consumidores perjudicados por practicas comerciales desleales: perspectiva del derecho europeo comparado», en laleydigital.es, § III.1.A. 
(«right to unwind»), como alternativa a la reducción del precio («right to a discount») y, en todo caso, a la indemnización de los daños sufridos por la práctica ${ }^{38}$.

Sin embargo, estas acciones solo se pueden ejercitar bajo determinadas condiciones. En primer lugar, el consumidor puede rescindir el contrato solo si la práctica prohibida es efectivamente un elemento fundamental en su toma de decisión, circunstancia que el mismo consumidor debe probar. El derecho a rescindir el contrato (right to unwind), además, se puede ejercitar solo dentro del límite de 90 días desde la conclusión del contrato, comunicando al comerciante la voluntad de devolver el producto, siempre que este siga siendo restituible. El método de cálculo para obtener una reducción del precio (discount) es altamente complejo y de todos modos queda sometido a una evaluación sobre la «gravedad» del comportamiento del comerciante, realizada por el juez. Ahora bien, debe observarse cómo también en este caso la introducción de una acción específica para los consumidores perjudicados por una práctica comercial no ha tenido un impacto notable sobre la tutela efectiva de los consumidores $^{39}$. El Consumer Redress for Misleading and Aggressive Practices (el estudio realizado por la Law Commission), al evaluar el posible impacto de la propuesta de modificación - que luego habría entrado en vigencia - inicialmente había estimado un crecimiento anual de las posibles acciones individuales entre 1000 y 5000 demandas adicionales al año. Sin embargo, desde la introducción del CPAR en 2014 hasta 2017, el número de demandas no excede las cien ${ }^{40}$.

Una acción sui generis, finalmente, fue introducida por el legislador belga ${ }^{41}$. La acción prevista por Bélgica, de hecho, proporciona al consumidor inducido a estipular un contrato al amparo de una práctica desleal la posibilidad de solicitar el reembolso de la cantidad pagada como contraprestación, pero sin la obligación de devolver el bien ${ }^{42}$. La normativa belga prevé

38 V. Statutory Instruments 2014, n. 870, The Consumer Protection (Amendment) Regulations, New Part 4A, Sections de 27A hasta 27L, en http://www.legislation.gov.uk/ uksi/2014/870/made.

${ }^{39}$ Bednarz, «Acciones individuales a disposición de los consumidores perjudicados por prácticas comerciales desleales: perspectiva del derecho europeo comparador», $\S$ III.3.

${ }^{40}$ En este sentido el estudio de Christine Riefa y Séverine Santier, «Unfair Commercial Practices Directive: remedying economic torts?», en Research Handbook on EU Tort Law, ed. por Paula Giliker (Cheltenham-Northampton: Edward Elgar, 2017), 314-315.

${ }^{41}$ Sobre la acción que se elijo en Bélgica y sobre su efectividad, v. Reinhard Steennot, «The Belgian Civil Remedy in Case of an Unfair Commercial Practice Towards a Consumer: an effective, proportionate and dissuasive sanction?», Business and Economics Series, n. ${ }^{\circ} 2$ (2012): 17-23.

${ }^{42}$ Art. 41, Loi 6 aprile 2010, Loi relative aux practiques du marché et à a protection $d u$ consommateur (AMPC) en https://www.wipo.int/edocs/lexdocs/laws/fr/be/be102fr.pdf. 
que esta acción se aplique de manera distinta, dependiendo de los presupuestos. En seis casos expresamente previstos, la reclamación se puede ejercitar directamente frente al comerciante, sin necesidad de acudir a la vía judicial: el consumidor solo debe, en un plazo temporal razonable, solicitar el reembolso correspondiente. Si este se niega a realizar el reembolso voluntariamente, el consumidor puede acudir a los tribunales para obtener aquél. Si se comprueba que la práctica de la que es víctima el consumidor se encuentra en los seis casos para los que se prevé la aplicación automática, el tribunal simplemente debe limitarse a aplicar la norma sin ningún margen de discreción ${ }^{43}$.

Es diferente el caso en el que una práctica con la cual se le ha inducido al consumidor a estipular un contrato no da lugar a la aplicación automática de la normativa. En estos casos, el tribunal tiene margen para decidir, dependiendo de los casos, si admite íntegramente o parcialmente la reclamación - p.ej. reduciendo el precio del bien o del servicio ${ }^{44}$ - o si la rechaza. Según lo previsto en el art. 41 AMPC, el juez, al tomar esta decisión, deberá evaluar la gravedad de la infracción, la medida en que el comportamiento económico del consumidor se ha visto influenciado por la práctica incorrecta, las consecuencias económicas para el consumidor, la proporcionalidad de la reclamación en relación con la infracción y el daño sufrido por el consumidor.

43 En particular, las prácticas abusivas mencionadas por el art. 41 AMPC - que se han sacado de las previstas en el listado del Anexo I de la Directiva 2005/29/CE - son: a) hacer afirmaciones materialmente inexactas en cuanto a la naturaleza y la extensión del peligro que supondría para la seguridad personal del consumidor o de su familia el hecho de que el consumidor no compre el producto; $b$ ) alegar que los productos pueden facilitar la obtención de premios en juegos de azar; $c$ ) proclamar falsamente que un producto puede curar enfermedades, disfunciones o malformaciones; $d$ ) crear la impresión de que el consumidor no puede abandonar el local hasta haber perfeccionado el contrato; $e$ ) realizar visitas en persona al domicilio del consumidor, ignorando las peticiones de éste de que el comerciante abandone su casa o no vuelva a personarse en ella; $f$ ) crear la impresión falsa de que el consumidor ha ganado ya, ganará, o conseguirá si realiza un acto determinado, un premio o cualquier otra ventaja equivalente, cuando en realidad: no existe tal premio o ventaja equivalente, o la realización de una acción relacionada con la obtención del premio o ventaja equivalente está sujeta a la obligación, por parte del consumidor, de efectuar un pago o incurrir en un gasto. A este propósito, se exprimieron perplejidades sobre la posibilidad de aplicar directamente la acción solo en estos casos; v. Steennot, «The Belgian Civil Remedy in Case of an Unfair Commercial Practice Towards a Consumer: an effective, proportionate and dissuasive sanction?», 18-19.

44 Steennot, «The Belgian Civil Remedy in Case of an Unfair Commercial Practice Towards a Consumer: an effective, proportionate and dissuasive sanction?», 19. 
Conviene subrayar, que el nexo causal deberá ser - al amparo de la ley belga - en todo caso probado por el consumidor ${ }^{45}$.

Incluso en el caso de Bélgica, que al menos a primera vista parece haber atribuido al consumidor una acción individual contra las prácticas desleales muy eficaz y exigente para el profesional ${ }^{46}$, se ha puesto en evidencia cómo el efectivo alcance de esta acción es en realidad profundamente limitado ${ }^{47}$. Las costas procesales (que frecuentemente no están justificadas por el escaso valor de las controversias que afectan a los consumidores), las dificultades probatorias, la excesiva discrecionalidad dejada a los tribunales, la ignorancia sobre la misma existencia de este instrumento - que no ha sido a día de hoy divulgado de manera suficiente por las Asociaciones de Consumidores belgas - han hecho prácticamente inefectiva esta acción particular, que de momento no está contribuyendo a la actuación de la legislación europea sobre prácticas desleales.

\section{Efectividad de la tutela y necesidad de full harmonszation en las acciones civiles contra las prácticas desleales: el recurso al sistema del derecho contractual europeo}

El análisis comparativo que se acaba de realizar - a pesar de no ser exhaustivo - parece llevar a dos conclusiones. La primera, que ya era previsible después de la adopción de la Directiva 2005/29/CE, es que no parece haber armonización en el derecho de los Estados miembros sobre acciones individuales para la tutela de los consumidores que hayan estipulado un contrato al amparo de una práctica abusiva. Probablemente, ello se debe a que el legislador europeo quiso evitar que la técnica de full harmonisation se aplicara también al Derecho privado, de manera particular al Derecho contractual $^{48}$.

45 Steennot, «The Belgian Civil Remedy in Case of an Unfair Commercial Practice Towards a Consumer: an effective, proportionate and dissuasive sanction?», 20.

46 Giovanni De Cristofaro, «L'attuazione dell Direttiva 2005/29/CE nell'ordinamento italiano: profili generali», en Pratiche commerciali scorrette e codice del consumo, ed. por De Cristofaro, 61.

47 Steennot, «The Belgian Civil Remedy in Case of an Unfair Commercial Practice Towards a Consumer: an effective, proportionate and dissuasive sanction?», 21-22.

48 V. Bednarz, «Acciones individuales a disposición de los consumidores perjudicados por prácticas comerciales desleales: perspectiva del derecho europeo comparador», § I; en este sentido v. también Whittaker, «The Relationship of the Unfair Commercial Practices Directive to European and National Contract Laws», 140-141. 
La segunda es la consecuente falta de efectividad del sistema de acciones, que, además de estar fragmentado, no garantiza una protección adecuada al consumidor.

Esto se puede constatar en los Estados que no han introducido acciones de Derecho privado específicas para el consumidor, en los que, como ya se ha explicado, este mantiene a su disposición los instrumentos «tradicionales» (como la anulabilidad para vicios del consentimiento). En dichos casos podría haber conductas de empresarios que no encajan con las definiciones de «dolo» o «violencia» o que no llevan a la nulidad del contrato, pero que, no obstante, han inducido a la contraparte a tomar una decisión de naturaleza comercial que de otra forma no se hubiera tomado, convirtiendo en irracional la elección de la parte débil de la relación ${ }^{49}$. En estas hipótesis la posible solución para el consumidor sería demandar la indemnización de los daños fundados sobre la base de responsabilidad precontractual. Sin embargo, muchas veces sería una acción menos ágil, comparada con las acciones contractuales, y que, de todos modos, tendría el efecto de mantenerlo vinculado a un contrato que no quería en absoluto y que concluyó solo como consecuencia de un comportamiento que el ordenamiento jurídico expresamente prohíbe.

Una falta de armonización similar existe también en los Estados Miembros que, por el contrario, introdujeron acciones contractuales específicas para la violación de prácticas abusivas. De hecho, se puede observar en el análisis que se acaba de realizar que: i) todos los Estados que adoptaron esta acción han elegido soluciones distintas (aunque orientadas hacia el mismo resultado, es decir, a la ineficacia del contrato viciado por prácticas abusivas); ii) las acciones previstas, en la mayoría de los casos, carecen de efectividad, son poco utilizadas o, de todas formas, son difícilmente accesibles para los consumidores, que muchas veces tampoco conocen su existencia.

La falta de armonización y de efectividad sobre la acción individual de la que dispone el consumidor que ha concluido un contrato bajo la influencia de una práctica desleal conlleva el riesgo de incumplir con los objetivos a los que expresamente aspiraba la normativa europea sobre prácticas desleales: incrementar la certidumbre jurídica y reducir la fragmentación en este ámbito normativo para aumentar la confianza de los consumidores en el mercado interior, por un lado, y para reducir las costas para las empresas, por el otro, con la finalidad de desarrollar el mercado único europeo.

${ }^{49}$ Gentili, «Pratiche sleali e tutele legali: dal modello economico alla disciplina giuridica», 61-64. 
La ausencia de acciones individuales para eliminar las consecuencias desfavorables de un acuerdo conseguido por un comportamiento desleal de la contraparte, impide que el consumidor perciba la utilidad de esta nueva normativa $^{50}$, y en consecuencia, no crecerá la confianza en el mercado, especialmente para las operaciones transfronterizas.

Un discurso en parte parecido puede hacerse para los empresarios. Como puede observarse ${ }^{51}$, a la luz de la normativa actual puede suceder que el consumidor, tenga a su disposición en su propio ordenamiento acciones para obtener, por ejemplo, la invalidez o la ineficacia del contrato viciado o para daños punitivos, que en cambio en el Estado del empresario quedan excluidos. Esto, se puede observar, lleva al aumento de los costes para las empresas que quieran efectuar ventas y promociones transnacionales y aumenta la desconfianza de los mismos comerciantes, que no quedan estimulados a ejercitar su actividad fuera de los confines nacionales.

Una consecuencia obvia de estas premisas es el fracaso de los objetivos de la Directiva 2005/29/CE y la falta de crecimiento del mercado interior, que sigue fragmentado ${ }^{52}$.

En este contexto se inscribe la Resolución del 13 enero de 2009 del Parlamento Europeo, ${ }^{53}$ que invita a la Comisión a retornar sobre el tema de la armonización del Derecho privado en relación con las prácticas abusivas. Del mismo modo, el reciente estudio de la Comisión sobre el impacto de la normativa de prácticas desleales ${ }^{54}$ muestra cómo los Estados Miem-

50 V. sobre este aspecto Luis González Vaqué, «La Directiva UE sobre las prácticas comerciales desleales: una cosa es predicar y otra dar trigo...», La Ley Digital (2013): § V.2.

51 Collins, «Harmonization by Example: European Laws against Unfair Commercial Practices», 116-117.

52 Bednarz, «Acciones individuales a disposición de los consumidores perjudicados por prácticas comerciales desleales: perspectiva del derecho europeo comparador», § II.2; Koutsias y Willet, «Uk implementation of the Unfair Commercial Practices Directive», 32; Collins, «Harmonization by Example: European Laws against Unfair Commercial Practices», 116.

${ }^{53}$ Resolución del Parlamento Europeo, de 13 de enero de 2009, sobre la transposición, aplicación y ejecución de la Directiva 2005/29/CE relativa a las prácticas comerciales desleales de las empresas en sus relaciones con los consumidores en el mercado interior y la Directiva 2006/114/CE sobre publicidad engañosa y publicidad comparativa (2008/2114 (INI)), http://www.europarl.europa.eu/sides/getDoc.do?pubRef=-//EP//TEXT+TA+P6-TA2009-0008+0+DOC+XML+V0//IT.

${ }^{54}$ Commission Staff Working Document, Report of the Fitness Check on Directive 2005/29/EC of the European Parliament and of the Council of 11 May 2005 concerning unfair business-to-consumer commercial practices in the internal market and amending Council Directive 84/450/EEC, Directives 97/7/EC, 98/27/EC and 2002/65/EC of the European Parliament and of the Council and Regulation (EC) No 2006/2004 of the European Parliament and of the Council ('Unfair Commercial Practices Directive'); [...] SWD(2017) 209 final, 92-93. 
bros acogerían con favor la introducción de acciones contractuales específicas para los consumidores víctimas de prácticas abusivas ${ }^{55}$. Estas acciones garantizarían aquella efectividad de tutela que actualmente no se logra y que se menciona no solo en la Directiva, sino también en otros actos de la Unión Europea ${ }^{56}$.

Un sistema de acciones individuales contra prácticas abusivas armonizado y efectivo, en definitiva, parece necesario. A este respecto, sin embargo, parece oportuno verificar si dicha falta de armonización y efectividad no se puede compensar recurriendo al ordenamiento jurídico europeo: a las normas ya vigentes en él y, donde estas no sean aplicables, a sus principios.

De hecho, la normativa vigente europea en protección de consumidores (acquis) incorpora algunos instrumentos que pueden ofrecer una tutela efectiva y armonizada a las víctimas de prácticas abusivas. Cabe entonces verificar, a la luz de una consideración sistemática del ordenamiento europeo, si existe realmente esta falta de acciones en el ámbito de prácticas desleales - como tradicionalmente parece pensarse - o si, al contrario, se pueden encontrar instrumentos a disposición de los consumidores efectivos y armonizados.

\section{Directivas europeas en tema de consumidores e interacción con la disciplina de prácticas desleales}

Esta reflexión, como se acaba de explicar, tiene como objetivo identificar eventuales acciones ya existentes en el sistema europeo, que puedan tutelar a los consumidores víctimas de prácticas abusivas. En este contexto, ciertamente, juegan un papel central las Directivas que forman el acquis communautaire del Derecho de consumidores. Aunque no regulan directamente la materia de prácticas desleales, como se tendrá ocasión de precisar,

55 En particular, los resultados de la consultación online muestran como el $95 \%$ de las asociaciones de consumidores, el $75 \%$ de los consumer respondent y el $75 \%$ de las Autoridades Publicas sean favorables a esta solución.

56 Aún en el ámbito de prácticas abusivas, a partir de la concretización del principio de efectividad, como se obtiene del art. 47 de la Charter e del art. 19(1)2 TEU, se ha hablado de «Constitutionalization of Remedies», llegando a afirmar la necesidad que el consumidor disponga de medios adecuados para liberarse de todos los «disadvantageous contractual consequences». V. sobre el tema Hans-W. Micklitz, «A Common Approach to the Enforcement of Unfair Commercial Practices and Unfair Contracts Terms», en The European Unfair Commercial Practices Directive. Impact, Enforcement Strategies and National Lecal Systems, ed. por Willem van Boom, Amandine Garde y Orkun Akseli (Surrey: Ashgate, 2014), 192-194. 
frecuentemente encajan con esta, proporcionando indirectamente a los consumidores acciones contractuales en los casos en que hayan concluido un negocio al amparo de comportamientos desleales de los empresarios y que, como se ha explicado, pueden representar la tutela actualmente más eficaz a disposición de los mismos consumidores ${ }^{57}$.

Las Directivas específicas prevén acciones individuales para los consumidores para cada una de las situaciones comprendidas en su ámbito de aplicación, alcanzando a menudo el objetivo de dar una tutela efectiva al consumidor.

Permaneciendo fieles al objeto de estudio de este trabajo, procederemos a analizar la interacción entre algunas de estas Directivas (las más relevantes) y la que ahora nos ocupa, centrando nuestra atención de manera particular en las acciones contractuales que aquellas contemplan.

\section{La Directiva 93/13/EC sobre cláusulas abusivas e invalidez de las cláusulas}

Se ha destacado repetidamente, tanto en la jurisprudencia europea como en la doctrina, que, aunque no hay una correlación absoluta ${ }^{58}$, las disciplinas relativas a las cláusulas abusivas de la Directiva de 93/13/EC y sobre prácticas desleales (que entre otras cosas en la versión inglesa se califican ambas como unfair) están estrechamente vinculadas.

De hecho, el mismo uso de cláusulas abusivas puede ciertamente calificarse como «práctica comercial» en el sentido indicado en el art. 2, lett. $d$ ) de la Directiva 2005/29/CE y que, cumpliéndose las condiciones, también puede ser - como suele ser- «desleal» ${ }^{59}$.

Esto parece más evidente a la luz de una conocida jurisprudencia europea $^{60}$ que precisó, por un lado, que una práctica desleal puede representar

57 Durovic, «The Subtle Europeanization of Contract Law: The Case of Directive 2005/29/EC on Unfair Commercial Practices», 742

58 De hecho, es sabido que la disciplina de las cláusulas abusivas toma como referencia el acto - el negocio estipulado entre comerciante y consumidor, que no ha sido negociadomientras que la de prácticas desleales hace referencia al comportamiento del profesional, que haya actuado de manera desleal antes, durante e incluso después la conclusión de una operación económica.

59 Salvatore Orlando, «L'utilizzo di clausole abusive come pratica commerciale scorretta», Obbligazioni e contratti, n. 4 (2009): 193.

${ }^{60}$ Asunto C-453/10, Jana Pereničová e Vladislav Perenič vs. SOS financ spol. s.r.o., Judgement of the European Court of Justice of 15 March 2015, ECLI:EU:C:2012:144. Sobre esta sentencia v., entre otros, Laura Valle, «La vessatorietà delle clausole, oltre la nullità parziale», Contratto e impresa/Europa, n. ${ }^{\circ} 1$ (2014): 100-136, 120-136; Giuseppe Marino, «Scorrettezza della pratica ed abusività della clausola nella disciplina del contratto 
uno de los factores que el juez nacional toma en consideración para valorar el carácter abusivo de una cláusula contractual ${ }^{61} \mathrm{y}$, por otro lado, que la misma introducción de una cláusula abusiva en el contrato con el consumidor puede considerarse como comportamiento desleal, al amparo del art. 5 de la Directiva 2005/29/CE ${ }^{62}$.

Por lo tanto, es frecuente que una cláusula abusiva constituya al mismo tiempo hipótesis de práctica desleal o que una práctica desleal se traduzca en una cláusula abusiva ${ }^{63}$. Piénsese, a modo de ejemplo, en los casos de engaño sobre la efectiva consistencia del precio de un bien o servicio objeto de la negociación; de la praxis se obtiene que muchas veces incluso este comportamiento encuentra expresión en cláusulas que perjudican al consumidor y que, cumpliéndose las condiciones, podrán calificarse como abusivas $^{64}$.

En todos estos casos, como es sabido, la cláusula abusiva, al amparo del art. 6 de la Directiva 93/13/EC es inválida ab initio o invalidable, dependiendo del sistema nacional que se tome en consideración. El consumidor entonces, si bien de manera indirecta, ya dispone de una acción prevista en el ordenamiento europeo.

Otra tutela a disposición del consumidor, en los casos examinados, es la acordada por el art. 5 de la Directiva 93/13/EC. De hecho, como es sabido, este artículo prevé que, en caso de duda sobre el sentido de una cláusula, prevalece siempre la interpretación más favorable a la parte débil del contrato, si ésta se propone al consumidor por escrito (la llamada interpretatio contra proferentem). Es evidente la posible relación con la disciplina de las

del consumatore», Contratto e impresa/Europa, n. $^{\circ} 1$ (2014): 137-179. En esta sentencia se califica como «engañosa» la práctica consistente en mencionar en un contrato de crédito una tasa anual equivalente inferior a la real: las provisiones relativas se pueden calificar como «cláusulas abusivas» del juez nacional y por lo tanto privas de eficacia.

La sentencia precisa que la apreciación del carácter desleal (engañoso) de dicha práctica no tiene incidencia directa sobre la validez del contrato de crédito concluido, que entonces - no obstante las demandas del consumidor - queda valido por lo restante (v. C-453/19, § 45-46).

61 Asunto C-453/10, § 43.

62 V. Conclusiones de la Abogado general sra. Verica Trestenjak, presentadas el 29 de noviembre de 2011, relativas al Asunto C-453/10, en http://curia.europa.eu/juris/document/ document.jsf; jsessionid=A4B0759451D4949458E296B663BCFEB4?text $=\&$ docid $=115483 \&$ pageIndex $=0 \&$ doclang $=E S \&$ mode $=1$ st $\&$ dir $=\& o c c=$ first $\&$ part $=1 \&$ cid $=16639$, en particular $\S$ $127-128$.

${ }^{63}$ Sobre la interacción de las dos disciplinas, entre otros, Francesco Bernardi, «L'uso di clausole vessatorie come pratica commerciale scorretta» (tesis doctoral, Università «La Sapienza» de Roma, 2017), https://core.ac.uk/download/pdf/144472905.pdf.

${ }^{64}$ Para este y otros ejemplos de la interacción entre cláusulas abusivas y prácticas desleales, v. Fachechi, Pratiche..., 153-155. 
prácticas engañosas, que muchas veces pueden traducirse en cláusulas contractuales ambiguas o poco claras. También en estos casos, en la legislación europea se encuentra ya un instrumento de tutela para el consumidor.

\section{La Directiva 1999/44/CE y la falta de conformidad de los bienes de consumo}

Otro ejemplo relevante de posible interacción entre prácticas comerciales desleales y la regulación contenida en otras Directivas europeas es ofrecido por la disciplina sobre la conformidad con el contrato de los bienes de consumo prevista en la Directiva1999/44/CE ${ }^{65}$.

El art. 2(1) de dicha Directiva impone al vendedor entregar al consumidor bienes conformes al contrato de venta y, en el segundo apartado, indica los casos en los que estos se presumen conformes. A través de una operación a contrario, se deduce del apartado $d$ ) de este artículo que un bien de consumo se puede reputar conforme al contrato - entre otros casos - cuando las calidades y las prestaciones de un bien no corresponden con las declaraciones públicas sobre las características concretas de los bienes, hechas por el vendedor, el productor o su representante, en particular en la publicidad o el etiquetado. El vendedor responde ante el consumidor de cualquier falta de conformidad que exista en el momento de la entrega del bien ${ }^{66}$. Es evidente, en esta disposición normativa, el posible entrelazamiento con la disciplina de prácticas abusivas: una declaración publicitaria que no sea conforme a la naturaleza o a las calidades del bien ofrecido puede ser fácilmente reconducida a la noción de práctica engañosa como está previsto en el art. 6 de la Directiva 2005/29/CE.

También en este caso, si como consecuencia de esta publicidad engañosa se ha estipulado un contrato entre empresario y consumidor, la Directiva 1999/44/CE prevé acciones individuales con las que el consumidor puede obtener tutela contra esta falta de conformidad, lo que supone accionar, si bien indirectamente, contra la misma práctica abusiva.

$\mathrm{Al}$ amparo del art. 3 de esta última Directiva, de hecho, el consumidor puede exigir que el vendedor ponga el bien en conformidad, mediante reparación o sustitución, sin cargo alguno en ambos casos, salvo que ello resulte imposible o desproporcionado. En el caso que nos ocupa - es decir, de las prácticas engañosas - la posibilidad de solicitar la reparación del bien no parece de utilidad particular, esto es porque en estos casos, generalmente,

65 Directiva 1999/44/CE del Parlamento Europeo y del Consejo del 25 mayo de 1999 sobre determinados aspectos de la venta y las garantías de los bienes de consumo.

66 Art. 3(1) de la Directiva 1999/44/CE. 
el comerciante da al consumidor informaciones no verdaderas o le entrega productos que no se corresponden con la descripción, pero no productos defectuosos que necesitan de reparación ${ }^{67}$. En cambio, la principal tutela del consumidor tendría que ser la posibilidad de substituir el producto por uno conforme a la descripción del vendedor.

Si ninguna de las dos hipótesis precedentes es posible, el consumidor tiene derecho a la reducción adecuada del precio o a la resolución del contrato $^{68}$.

De esta manera, del ordenamiento europeo se obtienen, nuevamente, acciones individuales a disposición de los consumidores víctimas de prácticas engañosas - consistentes p.ej. en declaraciones falsas sobre las calidades del producto vendido- que podrán exigir del vendedor un bien conforme a la descripción o, si es posible, una reducción del precio o la resolución del contrato, eliminando las consecuencias negativas resultantes del abuso del comportamiento del comerciante.

\section{La Directiva 2011/83/EU y el doble sistema de tutela}

Especialmente importante para nuestro análisis es la Directiva 2011/83/ EU sobre derechos de los consumidores ${ }^{69}$. Esta Directiva, de hecho, considerada en sus posibles interacciones con la disciplina de las prácticas abusivas, proporciona dos acciones individuales que permiten al consumidor eliminar las consecuencias dañosas de dichas prácticas.

a) El jus poenitendi. El primero de estos instrumentos es el derecho de desistimiento. Como es sabido, de hecho, en la disciplina de los contratos negociados entre consumidores y profesionales a distancia o fuera del establecimiento mercantil, la normativa europea asegura al consumidor - para compensar un posible perjuicio debido al factor sorpresa que caracteriza este tipo de praxis comercial ${ }^{70}$ - catorce días a partir de la puesta en posesión del bien o desde la conclusión del contrato, en función de que se trate de bienes o servicios, para ejercitar el llamado jus poenitendi ${ }^{71}$. En este pe-

67 Durovic, «The Subtle Europeanization of Contract Law: The Case of Directive 2005/29/EC on Unfair Commercial Practices», 746-747.

68 Art. 3(5) y 3(6) de la Directiva 1999/44/CE; cfr. sobre las acciones para falta de conformidad y en general sobre esta Directiva, Hans-W. Micklitzand e Norbert Reich, «Sale of consumers goods», en European Consumer Law..., 165-196, 180-185.

69 Directiva 2011/83/UE del Parlamento Europeo e del Consiglio sobre los derechos de los consumidores. Para observaciones sobre esta Directiva v. Francesco Ricci, I beni di consumo e la disciplina delle vendite aggressive (Bari: Cacucci, 2013), 147-156.

70 Ricci, I beni..., 46-50.

71 Art. 9, Directiva 2011/83/UE. 
riodo de tiempo, el consumidor puede dejar sin efecto el negocio, sin tener que justificar o motivar su decisión; solo tiene la carga de comunicar su intención a la contraparte. El periodo puede ampliarse hasta un año a partir del final del periodo de desistimiento inicial, en caso de que el comerciante no haya informado a la contraparte de la existencia de este derecho ${ }^{72}$.

A este respecto, se ha observado que las técnicas de contratación a distancia o fuera de los establecimientos mercantiles son las que, por un lado, encuentran mayor difusión, especialmente en el contexto del Mercado interior de la Unión Europea y de las ventas de carácter transnacional; y por otro, las que con mayor frecuencia dan lugar a prácticas desleales, al atraer directamente la atención del consumidor e inducirlo a contratar generalmente en plazos reducidos ${ }^{73}$. No es casualidad que varias de las prácticas previstas en el Anexo I de la Directiva 2005/29/CE, que se consideran desleales en cualquier circunstancia, en la praxis se den precisamente en este tipo de contrataciones ${ }^{74}$.

Por esta razón se puede fácilmente observar cómo entre las dos disciplinas - la de prácticas desleales y la de la contratación a distancia o fuera de establecimientos - existe una fuerte relación de complementariedad ${ }^{75}$ que hace muy frecuente su integración.

El jus poenitendi se convierte, indirectamente, en un sencillo instrumento para los consumidores que hayan estipulado uno de los dos contratos previstos en la Directiva 2011/83/EU al amparo de prácticas desleales y que quieran eliminar las consecuencias dañosas de dicha operación ${ }^{76}$.

b) Intertia Selling. La disciplina de los suministros no solicitados (Inertia Selling), aunque constituye una operación muy específica, es un importante punto de intersección entre la disciplina de las prácticas desleales y el Derecho contractual, siendo dicha intersección explicitada por el mismo dictado normativo de la Directiva 2011/83/UE.

El suministro no solicitado, de hecho, es una de las treinta y una prácticas enumeradas en el Anexo I de la Directiva 2005/29/CE ${ }^{77}$ - y como tal, y como ya se ha destacado, se considera desleal en cualquier circunstancia-

72 Art. 10 Directiva 2011/83/UE.

73 Fachechi, Pratiche..., 108.

${ }^{74}$ Cfr., p.ej. n. ${ }^{\circ}$ 6), 7), 25), 26), Anexo I, Directiva 2005/29/CE. Para otros ejemplos de interacción entre las disciplinas v. otra vez Fachechi, Pratiche..., 109-112.

75 Así, expresamente Fachechi, Pratiche..., 112 que habla de «nesso di complementarietà».

76 Marco Loos, «Rights of Withdrawall», en Modernising and Harmonising Consumer Contract Law, ed. por Geraint Howells y Reiner Schlze (Munich: Sellier, 2009), 237-278, 245-249.

77 V. n. $\left.{ }^{\circ} 29\right)$, Anexo I, Directiva 2005/29/CE. 
y es mencionado expresamente por la normativa de 2011, que prevé una acción sui generis a disposición del consumidor que haya sido su víctima.

El art. 27 de la Directiva 2011/83 UE exime al consumidor de toda obligación de entregar contraprestación alguna en caso de suministro no solicitado de bienes, agua, gas, electricidad o calefacción mediante sistemas urbanos, de contenido digital o de prestación de servicios no solicitada, especificando que en estos casos la falta de respuesta del consumidor no se considera consentimiento.

El caso de Inertia Selling, por lo tanto, es uno de los pocos casos de acción individual desarrollada e introducida a nivel europeo que, de manera indirecta, tiene como objetivo contrastar los efectos negativos de una práctica comercial desleal ${ }^{78}$.

\section{Prácticas comerciales desleales y el deber de buena fe}

De la exposición que se acaba de realizar, se desprende cómo, en un análisis más detallado del ordenamiento europeo, aunque no se prevea expresamente una armonización plena en tema de acciones individuales contra prácticas comerciales desleales, en realidad existen numerosos casos y sectores en los que - si bien de manera indirecta - hay acciones individuales a disposición de los consumidores para eliminar los efectos dañosos de los contratos estipulados bajo la influencia de dicho comportamientos. En estas condiciones, contra la mayoría de los casos de prácticas desleales ya se puede identificar una acción especialmente prevista por el Derecho europeo; en estos casos, por tanto, de algún modo, la armonización ya existe. Deste esta perspectiva, la falta de tutela y armonización para este tipo de hipótesis sería solo «aparente» ${ }^{79}$, porque el consumidor ya dispone de instrumentos idóneos para la tutela de sus derechos frente comportamientos desleales de los profesionales impulsados por el legislador europeo.

A pesar de lo dicho, el gran alcance de la noción de «práctica comercial desleal» lleva a constatar cómo ciertamente existen casos no incluidos en el acquis comunitario y que, por ello, quedan fuera del ámbito de armonización, corriendo el riesgo, por las razones ya explicadas, de que los consumidores se vean privados de acciones de efectivo alcance.

En estos casos el camino viable para llenar el vacío normativo, garantizando una tutela efectiva y armonizada para el consumidor, parece ser el

78 Durovic, «The Subtle Europeanization of Contract Law: The Case of Directive 2005/29/EC on Unfair Commercial Practices», 748.

79 En óptica italiana, habla de gap de acciones solo aparente Alessia Fachechi, «Pratiche commerciali scorrette e (apparente) gap normativo», Studium Iuris, n. ${ }^{\circ} 2$ (2015): 181-189. 
del uso de un principio de probada relevancia en el ámbito del Derecho europeo $^{80}$ : el principio de buena fe.

Como es sabido, de hecho, la buena fe objetiva tiene una relevancia indiscutible en el panorama jurídico europeo, si bien con connotaciones particulares de Estado a Estado y con diferencias más o menos profundas. Es reflejo de lo dicho el amplio énfasis de la buena fe objetiva en los P.E.C.L. (Principios de Derecho Común Europeo de Contratos), en el D.C.F.R. (Draft Common Frame of Reference) $^{81}$ y en el C.E.S.L. (Common European Sales Law) ${ }^{82}$.

En la misma introducción al D.C.F.R. se ha puesto de manifiesto cómo una de las posibles consecuencias a la que tiende el principio de buena fe es la promoción de prácticas de mercado honestas, con el fin de evitar que una parte se desvíe de la correcta praxis comercial para obtener una ventaja injusta a expensas de la otra ${ }^{83}$. Ahora bien, se observa con facilidad cómo la ratio de la disciplina de las prácticas desleales se conecta de manera evidente con los valores de la buena fe; es más, puede evidentemente encontrar su mismo fundamento en este principio.

La cuestión de la acción individual en la violación de normas introducidas por la Directiva 2005/29/CE parece, por lo tanto, estrechamente relacionada con la más general - e igualmente debatida - de las acciones individuales contra la violación del deber de buena fe.

Sin profundizar en este debate, nos limitaremos a observar cómo, según una opinión muy extendida, la identificación de las acciones que tienen su fundamento en la violación del principio de buena fe requiere distinguir entre normas de comportamiento de los contratantes y normas de validez del contrato. De la violación de las primeras, sea en la fase prenegocial sea en aquella de actuación de la relación contractual, se genera

${ }^{80}$ Para un estudio sobre el principio de buena fe en derecho europeo, v. Good Faith in European Contract Law, ed. por. R. Zimmermann y S. Whittaker (Cambridge: Cambridge University Press, 2008).

${ }^{81}$ Sobre las disposiciones que mencionan el principio de buena fe, contenidas en estos dos actos v. Ricci, «Buona fede e rimedi», 639-641. Como observado por el mismo Autor, la concordancia de posiciones entre D.C.F.R. y P.E.C.L. no sorprende, ya que el primero queda explícitamente basado en parte sobre una versión revisada del secundo.

${ }^{82}$ Sobre la buena fe en el C.E.S.L. v. Pasquale Stanzione, «Il Regolamento di diritto comune europeo della vendita», I contratti, n. ${ }^{\circ} 7$ (2012): 624-634, 629-633.

83 «Introduction», en Principles, Definitions and Model Rules of European Private Law. Draft Common Frame of Reference (DCFR). Outline Edition, Prepared by the Study Group on a European Civil Code and the Research Group on EC Private Law (Acquis Group) Based in part on a revised version of the Principles of European Contract Law Edited by Christian von Bar, Eric Clive and Hans Schulte-Nölke and Hugh Beale, Johnny Herre, Jérôme Huet, Matthias Storme, Stephen Swann, Paul Varul, Anna Veneziano and Fryderyk Zol, (Munich: Sellier, 2009), § 33 . 
una responsabilidad - que en unos casos expresamente previstos por la ley puede llevar a la ineficacia del contrato - pero dicha violación, como regla general, no incide sobre la validez del acto negocial ${ }^{84}$. Por lo tanto, conforme a esta doctrina, la violación del deber de buena fe, aunque ocurrida en la fase de los tratos preliminares o durante el curso del procedimiento de formación del contrato e incluso si esta violación se traduce en un comportamiento que determine la conclusión de un contrato pernicioso para la parte víctima de la conducta desleal, nunca llevaría a la invalidez del acto, sino que daría la posibilidad a la contraparte de solicitar la indemnización de los daños ${ }^{85}$.

No obstante, como ha sido observado, una consideración más profunda del sistema europeo parecería llevar a una conclusión diferente ${ }^{86}$. Una de las normas que hacen referencia al principio de buena fe es el art. 2(2) de la C.E.S.L., en virtud del cual la violación del deber de buena fe «may preclude the party in breach from exercising or relying on a right, remedy or defence which that party would otherwise have, or may make the party liable for any loss thereby caused to the other party». Esta norma, como es sabido, encuentra una concreta actuación en las provisiones que establecen que puede considerarse como no realizada o incumplida una condición cuyo cumplimento ha sido impedido o provocado por un comportamiento contrario a la buena fe de la parte que habría sido, respectivamente, dañada o favorecida (art. 16:102 P.E.C.L.; art. III 1:106(4), D.C.F.R. $\left.{ }^{87}\right)$.

${ }^{84}$ La bibliografía sobre el tema es muy vasta. V. para el derecho francés, Pascal Ancel, «Les sanctions du manquement à la bonne foi contractuelle en droit français à la lumière du droit québécois», Revue juridique Témis 45, (2011): 87-113; con respecto al derecho italiano, entre otros, Giovanni D'Amico, Regole di validità e principio di correttezza nella formazione del contratto (Napoli: Edizioni Scientifiche Italiane, 1996); Giovanni D’Amico, «Regole di validità e di comportamento nella formazione del contratto», Rivista di diritto civile, n. ${ }^{\circ} 1$ (2002): 37-61; Giuseppe Vettori, «Le asimmetrie informative tra regole di validità e regole di responsabilità», Rivista di diritto privato, (2003), 241-254; Giovanni Perlingieri, L'inesistenza della distinzione tra regole di comportamento e di validità nel diritto italoeuropeo (Napoli: Edizioni Scientifiche Italiane, 2013).

85 En la jurisprudencia italiana, se pronunciaron en este sentido las conocidas sentencias gemelas Cass. civ., Sez. un., 19 diciembre de 2007, n..$^{\circ} 26724$ e 26725, las dos en Banca Dati Pluris, http://pluris-cedam.utetgiuridica.it/main.html; en la doctrina, sobre estas sentencias, v. entre otros Giuseppe Vettori, «Regole di validità e di responsabilità di fronte alle Sezioni Unite. La buona fede come rimedio risarcitorio», Obbligazioni e contratti, (2008): 104-108; de manera crítica, Aurelio Gentili, «Disinformazione e invalidità: i contratti di intermediazione dopo le Sezioni Unite», I contratti, n. ${ }^{\circ} 4$ (2008): 393-402.

${ }^{86}$ Ricci, «Buona fede e rimedi», 645-647.

${ }^{87}$ Como es sabido, este principio encuentra directa aplicación en las disposiciones nacionales: cfr. art. 1359 del Codice Civile italiano, y el § 157 BGB alemán. 
Trasladado al contexto de las prácticas desleales, este principio de carácter general lleva a la conclusión de que el comerciante no puede aprovecharse de un contrato que es directa consecuencia de su comportamiento desleal y, como tal, contrario a buena fe. Conferir al consumidor solo la posibilidad de exigir la indemnización de los daños parece ineficiente por dos razones. Por un lado, la indemnización de los daños podría conllevar problemas de inefectividad - que ya se han identificado como una de las problemáticas principales relativas a la tutela individual contra prácticas desleales - siendo, como ya se ha observado, un instrumento poco ágil y a menudo difícil de obtener, debido a las dificultades propias de la acción. Por otro lado, parece casi paradójico mantener al consumidor vinculado a un contrato (o parte de este) que él no quería (o que no quería solo parcialmente) y que se ha concluido en su perjuicio por un comportamiento que, además de ser contrario a uno de los principios fundamentales del Derecho contractual europeo, está expresamente prohibido, y al mismo tiempo darle la posibilidad de solicitar una indemnización por las mismas razones ${ }^{88}$.

Al contrario, parece más coherente y eficiente considerar que el contrato (o parte de este) que sea el resultado de una práctica desleal no pueda vincular al consumidor ${ }^{89}$.

Esta consideración, por un lado, se confirma por las soluciones ya adoptadas por muchos de los Estados que introdujeron acciones específicas para la violación de la prohibición de prácticas desleales y, por otro, es coherente con la mayoría de las soluciones anteriormente individuadas que derivan de la yuxtaposición de esta disciplina con otras Directivas sobre Derecho de consumidores.

\section{Conclusiones}

Los sistemas de acciones individuales establecidos por los Estados contra prácticas comerciales desleales, como se ha puesto en evidencia, son hoy muy distintos entre ellos. Además, en muchos casos resultan ineficientes, debido a las dificultades de los consumidores a la hora de solicitarlos. En la doctrina alguien incluso ha relevado la inutilidad de la introducción de estas acciones, que no serían la solución apropiada para

88 V. Matera «Le pratiche commerciali scorrette e il sistema dei rimedi», $\S 3$.

89 A la misma conclusión, enfocada en derecho italiano, llega Ricci, «Buona fede e rimedi», 647, que observa como «la negazione degli effetti di una fattispecie nella quale la violazione del dovere di buona fede s'inserisce come effetto impeditivo della realizzazione dei valori tutelati dall'ordinamento, a ben vedere, costituisce non l'eccezione, ma la regola». 
asegurar protección a los consumidores víctimas de comportamientos desleales de las contrapartes ${ }^{90}$.

Ciertamente esta situación de incertidumbre junto con la ineficiencia de las acciones individuales que hasta ahora los Estados han asegurado implica, por un lado, una tutela inadecuada para los consumidores y, por otro, un perjuicio también para los comerciantes que operan en el mercado transnacional. Directa consecuencia es el fracaso de los objetivos que la Directiva quería conseguir: incrementar la confianza de los consumidores en el mercado único y en consecuencia hacer crecer éste. No son estas acciones, entonces, el instrumento que actualmente garantiza protección adecuada a los consumidores.

Sin embargo, un análisis sistemático del ordenamiento europeo, permite concluir que, en realidad, ya desde el acquis communautaire en el ámbito de los consumidores se puede deducir un sistema de acciones a disposición de los consumidores. Dichas acciones, que están previstas en otras Directivas, aunque no reglamentan directamente casos de prácticas comerciales desleales, terminan interactuando con estas, ofreciendo al consumidor una tutela (indirecta) que resulta ciertamente armonizada y, en muchos casos, efectiva.

Si bien estos casos de interacción son numerosos y garantizan un alto nivel de tutela al consumidor, no pueden llegar a cubrir todas las hipótesis de prácticas desleales. En dichas situaciones parece necesario recurrir a uno de los principios más importantes del Derecho contractual europeo: la buena fe. Considerando todas las prácticas desleales como una implícita violación de este principio y asumiendo como existente en el ordenamiento europeo la regla por la que el contrato (o parte de este) concluido exclusivamente por violación de la buena fe de uno de los contratantes (o que se hubiera concluido a condiciones distintas sin dicha violación) no puede vincular la parte victima del abuso, se llega a una solución de utilidad central.

El recurso a este principio, más que otras soluciones, de hecho, tiene sus ventajas. En primer lugar, armoniza los éxitos de la contratación mediante prácticas desleales; así, cumpliéndose los requisitos y no habiendo otra acción más específica en el ordenamiento, el profesional no puede aprovecharse, en perjuicio del consumidor, de un contrato concluido al amparo de dichas prácticas. Por otro lado, respeta las peculiaridades de los Derechos nacionales de los Estados miembros, superando las argumentaciones objetadas por quienes se posicionaron en contra de la posibilidad de introducir legislativamente una acción única para todos los Estados respecto a la violación de prácticas desleales.

90 Bednarz, «Acciones individuales a disposición de los consumidores perjudicados por prácticas comerciales desleales: perspectiva del derecho europeo comparador», § III.3. 


\section{Acerca del autor}

Donato Maria Matera es Profesor Ayudante de Derecho Privado en la Universidad LUM «Jean Monnet» de Bari-Casamassima, con el Prof. D. Francesco Ricci. Sus ámbitos principales de investigación son el derecho de los consumidores, el derecho contractual y el derecho privado europeo. $\mathrm{Su}$ Tesis final de grado (sobre prácticas comerciales desleales) ha sido desarrollado en Italia y en España en la Universidad Deusto de Bilbao, donde trabajó con la prof. Dña.Inmaculada Herbosa Mertínez. Este trabajo obtuvo una mención especial por la Comisión Examinadora (summa cum laude), por la calidad de la investigación. Participó en el proyecto internacional de investigación «Principi, clausole generali, argomentazione e fonti del diritto», estudiando los remedios de derecho privado que el ordenamiento jurídico italiano pone a disposición de los consumidores contra prácticas comerciales desleales. Como resultado de este proyecto publicó el trabajo «Le pratiche commerciali scorrette e il sistema dei rimedi», en el libro «Princìpi, clausole generali, argomentazione e fonti del diritto», ed. por Francesco Ricci, Milano, 2018, Giuffrè Francis Lafebvre.

\section{About the author}

Donato Maria Matera is Teaching Assistant in Private Law at the University LUM «Jean Monnet» of Bari-Casamassima, with Prof. Francesco Ricci. His main fields of research are: consumer law, contract law and European private law. He carried out the research for his Master's degree thesis (about Unfair Commercial Practices) in Italy, with prof. Francesco Ricci and Spain, at the University of Deusto, Bilbao, where he worked with prof. Inmaculada Herbosa Mertínez. This thesis was awarded the special distinction summa cum laude by the Graduation Committee for the quality of its research. He participated in the international research project «Principi, clausole generali, argomentazione e fonti del diritto», where he studied the Italian private remedies against unfair commercial practices. As a result of this project he published the paper «Le pratiche commerciali scorrette e il sistema dei rimedi», in the book «Princìpi, clausole generali, argomentazione e fonti del diritto», ed. by Francesco Ricci, Milano, 2018, Giuffrè Francis Lafebvre. 


\section{Derechos de autor}

Los derechos de autor (para la distribución, comunicación pública, reproducción e inclusión en bases de datos de indexación y repositorios institucionales) de esta publicación (Cuadernos Europeos de Deusto, CED) pertenecen a la editorial Universidad de Deusto. El acceso al contenido digital de cualquier número de Cuadernos Europeos de Deusto es gratuito inmediatamente después de su publicación. Los trabajos podrán leerse, descargarse, copiar y difundir en cualquier medio sin fines comerciales y según lo previsto por la ley; sin la previa autorización de la Editorial (Universidad de Deusto) o el autor. Así mismo, los trabajos editados en CED pueden ser publicados con posterioridad en otros medios o revistas, siempre que el autor indique con claridad y en la primera nota a pie de página que el trabajo se publicó por primera vez en CED, con indicación del número, año, páginas y DOI (si procede). Cualquier otro uso de su contenido en cualquier medio o formato, ahora conocido o desarrollado en el futuro, requiere el permiso previo por escrito del titular de los derechos de autor.

\section{Copyright}

Copyright (for distribution, public communication, reproduction and inclusion in indexation databases and institutional repositories) of this publication (Cuadernos Europeos de Deusto, CED) belongs to the publisher University of Deusto. Access to the digital content of any Issue of Cuadernos Europeos de Deusto is free upon its publication. The content can be read, downloaded, copied, and distributed freely in any medium only for non-commercial purposes and in accordance with any applicable copyright legislation, without prior permission from the copyright holder (University of Deusto) or the author. Thus, the content of CED can be subsequently published in other media or journals, as long as the author clearly indicates in the first footnote that the work was published in CED for the first time, indicating the Issue number, year, pages, and DOI (if applicable). Any other use of its content in any medium or format, now known or developed in the future, requires prior written permission of the copyright holder. 